\title{
Clinical Evaluation and Management Outcomes of Isolated Anterior Wall Frontal Sinus Fractures Fixation with Low Profile Miniplates
}

\author{
AHMED A.A. ALI, M.D.* and MOHAMMED H. OSMAN, M.D.** \\ The Department Plastic Surgery, Faculty of Medicine, South Valley University* and The Maxillofacial Surgery Unit, \\ Faculty of Medicine, Assiut University**
}

\begin{abstract}
Background: Frontal sinus fractures are relatively common with high-velocity injury trauma. Isolated anterior wall fractures represent one third of all cases. The main goals of fixation are to restore the premorbid aesthetic condition and to preserve a safe and functional sinus. The ideal plating system used for fixation of the anterior frontal wall fractures is the micro plating system owing to its many advantages. However, it is also feasible to utilize the low-profile miniplating system as it has the same advantages.
\end{abstract}

Patients and Methods: A prospective study conducted on patients admitted to trauma unit in two departments (Maxillofacial department; Assiut University Hospital and Plastic Surgery Department; Qena University Hospital) from August 2017 to July 2019 (two years' duration). The study included all patients with anterior wall fracture of frontal sinus that needed open reduction and internal fixation (ORIF) with sinus preservation. Materials used: Low profile miniplate system; KLS Martin compact system; $1.5 \mathrm{~mm}$ craniofacial plates with thickness $0.7 \mathrm{~mm}$, miniscrew $1.5 \mathrm{~mm}$ with $5 \mathrm{~mm}$ in length and drill bit $1.1 \mathrm{~mm}$ diameter. Statistical analysis: Data was analyzed using the Statistical Package for Social Sciences (SPSS) version 22. $p$-value $<0.05$ was considered significant.

Results: Follow-up period ranged from 6-12 months. Clinical data revealed that none of the patients complained from these miniplates concerning its palpability under the skin, sensitivity to temperature changes. No plate exposure or extrusion recorded. Only two patients had wound infections that resolved by antibiotic therapy. Patients complained only from minor symptoms such as pain, supraorbital paresthesia and facial edema. CT imaging showed good fracture healing, good alignment of the anterior wall and no plate failure (fracture). Patients were satisfied with restoration of the forehead contour and excellent aesthetic results.

Conclusion: Isolated anterior wall frontal sinus fractures are common due to high incidence rate of motor car accidents in our country. Main lines of treatment aimed to restore a safe functional sinus, prevent forehead contour deformity and obtain good aesthetic results. These goals can be obtained by fracture fixation with this low profile miniplate system with resultant patient satisfaction.

Key Words: Frontal sinus - Isolated anterior wall fractureMiniplate fixation.
INTRODUCTION

Frontal sinus fractures represent $5-15 \%$ of craniomaxillofacial fractures, relatively one third of these fractures is confined to the anterior table, while two thirds of them are combination of anterior table, nasofrontal duct and posterior table. Isolated posterior table fractures are rare and represents only $1 \%$. Thick cortical bone of the anterior table makes it more resistant to fracture than other facial bones. So, frontal bone and sinus require significant force with high-velocity injury to be fractured [1].

Management of frontal sinus fractures aims at reestablishment of aesthetic forehead contour, renewal of a safe and functional sinus, protection of intracranial contents and avoidance of associated adverse outcomes. Inadequately repaired fractures can lead to chronic sinusitis, forehead contour deformity, mucocele, mucopyocele, meningitis and brain abscess [2]. Options for management include: conservation, open reduction and internal fixation of the anterior table, endoscopic repair, sinus obliteration as well as cranialization [3,4].

Treatment options are based on the degree of fracture displacement, patency of nasofrontal duct and associated intracranial injuries. So, according to degree of displacement of the anterior table detected by computed tomographic imaging (CT): if it is minimal ( $<4 \mathrm{~mm}$ table width), it needs observation only but in moderate $(4-6 \mathrm{~mm})$ to severe $(>6 \mathrm{~mm})$, open reduction and internal fixation is required to restore the pre morbid aesthetic appearance. Assessment of patency of naso frontal duct is mandatory to either conserve (patent duct) or obliterate the sinus (obstructed duct), also displacement of the posterior table more than table width $(1 \mathrm{~mm})$ is indicator for cranialization [5]. 
From a biomechanical point of view, a micro plating system $(1.1 / 1.3 \mathrm{~mm})$ is used for fixation of anterior table for this non-loading area as it has the advantages of being non-palpable under the skin, less liability to temperature sensitivity, less infection, no artifact on computed tomographic imaging (CT) and no corrosion $[6,7]$.

However, it is feasible to utilize the low-profile miniplating system with the same outcomes.

In this study, fixation of anterior table with a low profile miniplate system $(1.5 \mathrm{~mm} / 0.7 \mathrm{~mm}$ thickness with miniscrew $1.5 \mathrm{~mm}$ with $5 \mathrm{~mm}$ in length) was applied and clinically evaluated for its palpability under the skin, temperature sensitivity, infection and fracture healing on computed tomographic imaging (CT).

\section{PATIENTS AND METHODS}

Study design: This prospective study conducted on patients admitted to trauma unit in two Departments (Maxillofacial Department; Assiut University Hospital and Plastic Surgery Department; Qena University Hospital) from August 2017 to July 2019 (two years' duration).

The study included all patients with anterior wall fracture of frontal sinus that needed open reduction and internal fixation (ORIF) with sinus preservation. Patients with nasofrontal duct (NFD) damage that needed sinus obliteration, displaced posterior wall fracture that needed cranialization (>1mm table width), cranial fractures and panfacial fractures were excluded. Noncompliant patients for long-term follow-up were also excluded from the study.

The study was approved by faculty ethical committee for research in human studies. Informed consent and written releases from patients for their photos were signed.

Materials used: Low profile miniplate system; KLS Martin compact system; $1.5 \mathrm{~mm}$ craniofacial plates with thickness $0.7 \mathrm{~mm}$, miniscrew $1.5 \mathrm{~mm}$ with $5 \mathrm{~mm}$ in length and drill bit $1.1 \mathrm{~mm}$ diameter.

Rationale for use of these plates: Our patients had thick forehead skin with its sebaceous nature that can protect against their palpability under the skin and are less sensitive in temperature changes (hot and cold weather). Also; from the biomechanical point of view; these plates are feasible; it can afford less load on bone fragment as in other areas in upper and midfacial regions.

Parameters: Data collected in a clinical sheet for every patient with the following parameters: Gender, age, etiology of trauma, computed tomographic (CT) analysis (fracture side, degree of fracture displacement and comminution, supraorbital rim/orbital roof involvement and associated other facial fractures), surgical approach, materials used for fixation; Table (1).

Neurological consultation was mandatory in all cases. Patients with cerebrospinal fluid (CSF) rhinorrhea (positive halo test), neurological injuries referred to neurosurgeons and excluded from our record. Patients with CT evaluation that showed significant displacement of posterior table, pneumocephalus and other cranial fractures were discarded.

\section{Surgical technique:}

Surgical intervention had delayed until facial edema resolved with time elapse after trauma (57 days). Preoperative medications such as antibiotics (penicillin/cephalosporin) and analgesics were administrated and continued postoperatively for one week. All cases underwent surgical procedures in supine position with head lift under general anesthesia. Local infiltration of the incision line with $1 \mathrm{mg}$ epinephrine diluted with $200 \mathrm{ml}$ saline solution $(1: 200,000)$ to achieve hemostasis performed mandatory.

We followed the following steps: Firstly, exposure of the fracture. Secondly, assessment of nasofrontal duct patency (injection of diluted methylene blue into it). Only cases with patent duct was recorded and we followed a sinus conservation protocol. Lastly, fixation with low profile titanium miniplate $(1.5 \mathrm{~mm})$ system was performed. A suction drainage inserted and wound closed meticulously.

Methods of evaluation: Plates evaluated clinically for its palpability under the skin, temperature sensitivity, infection, exposure and extrusion. Radiological evaluation by CT included: Fracture healing, alignment and complication of union.

Statistical analysis: Data was analyzed using the Statistical Package for Social Sciences (SPSS) version 22. $p$-value $<0.05$ was considered significant. 
Table (1): Data of patients enrolled in the study.

\begin{tabular}{|c|c|c|c|c|c|c|c|c|c|}
\hline \multirow[b]{2}{*}{ No. } & \multirow[b]{2}{*}{ Gender } & \multirow[b]{2}{*}{$\begin{array}{c}\text { Age } \\
\text { (years) }\end{array}$} & \multirow[b]{2}{*}{ Etiology } & \multicolumn{4}{|c|}{ CT Imaging } & \multirow{2}{*}{$\begin{array}{l}\text { Surgical } \\
\text { approach }\end{array}$} & \multirow[b]{2}{*}{$\begin{array}{l}\text { Methods of } \\
\text { fixation }\end{array}$} \\
\hline & & & & $\begin{array}{l}\text { Fracture } \\
\text { side }\end{array}$ & $\begin{array}{l}\text { Degree of } \\
\text { displacement and } \\
\text { comminution }\end{array}$ & $\begin{array}{l}\text { Supraorbital } \\
\text { rim/orbital } \\
\text { roof }\end{array}$ & $\begin{array}{l}\text { Associated facial } \\
\text { fracture }\end{array}$ & & \\
\hline 1 & Male & 35 & MCA & Left & Severely displaced & None & None & Coronal & Miniplates \\
\hline 2 & Male & 22 & MCA & Right & Severely displaced & Supraorabital rim & $\begin{array}{l}\text { Right } \mathrm{ZMC}^{*} \\
\text { Right } \\
\text { (frontozygomatic suture) }\end{array}$ & Coronal & Miniplates \\
\hline 3 & Male & 18 & Assault & Right & Moderatly displaced & None & None & Coronal & Miniplates \\
\hline 4 & Male & 29 & Assault & Left & Moderately displaced & None & None & $\begin{array}{r}\text { Preexisting } \\
\text { laceration }\end{array}$ & Miniplates \\
\hline 5 & Male & 22 & MCA & Right & Moderately displaced & None & None & Coronal & Miniplates \\
\hline 6 & Male & 34 & MCA & Right & Moderately displaced & Supraorabital rim & None & $\begin{array}{r}\text { Preexisting } \\
\text { laceration }\end{array}$ & Miniplates \\
\hline 7 & Male & 16 & MCA & Bilateral & Severely displaced & Supraorabital rim & $\begin{array}{l}\text { Right ZMC** } \\
\text { (none displaced) }\end{array}$ & Coronal & Miniplates \\
\hline 8 & Male & 40 & MCA & Left & Moderately displaced & Supraorabital rim & $\begin{array}{l}\text { Left } \\
\text { zygomatic arch }\end{array}$ & Coronal & Miniplates \\
\hline 9 & Male & 39 & MCA & Bilateral & Comminuted & Supraorabital rim & NOE* type I & Coronal & Miniplates \\
\hline 10 & Male & 19 & MCA & Bilateral & Comminuted & Supraorabital rim & Nasal & Coronal & Miniplates \\
\hline 11 & Male & 35 & Assault & Left & Moderately displaced & None & None & Coronal & Miniplates \\
\hline 12 & Male & 17 & MCA & Bilateral & Moderately displaced & None & $\begin{array}{l}\text { Right ZMC* } \\
\text { (frontozygomatic) }\end{array}$ & Coronal & Miniplates \\
\hline 13 & Male & 20 & MCA & Right & Moderately displaced & Supraorabital rim & $\begin{array}{l}\text { Right ZMC* } \\
\text { (zygomatico-maxillary } \\
\text { buttress) } \\
\text { none displaced }\end{array}$ & Coronal & Miniplates \\
\hline 14 & Male & 45 & Assault & Right & Severely displaced & Supraorabital rim & $\begin{array}{l}\text { Right ZMC } \\
\text { (frontozygomatic) }\end{array}$ & Coronal & Miniplates \\
\hline 15 & Male & 24 & MCA & Bilateral & Comminuted & Supraorabital rim & None & Coronal & Miniplates \\
\hline 16 & Male & 47 & MCA & Right & Comminuted & Supraorabital rim & $\begin{array}{l}\text { Right ZMC* } \\
\text { (non-displaced) }\end{array}$ & $\begin{array}{r}\text { Preexisting } \\
\text { laceration }\end{array}$ & Miniplates \\
\hline
\end{tabular}

* ZMC (Zygomaticomaxillary complex), NOE (Naso-orbital-ethmoid).

\section{RESULTS}

Sixteen male patients were enrolled in this study. Their ages ranged from 16-47 years (mean: 31.5 years). The commonest etiology of trauma was motor car accident (MCA) that recorded in 12 patients followed by assault from others in 4 patients. Clinical findings revealed periorbital edema and ecchymosis in 12 patients, paresthesia in supraorbital/supratrochlear nerve in 9 patients, forehead depression and contour deformity in 7 patients, palpable step off in 6 patients and forehead laceration in 4 patients.

Computed tomographic (CT) findings, showed: moderate displacement of anterior wall $(4-6 \mathrm{~mm})$ in 8 patients and severe displacement $(>6 \mathrm{~mm})$ in 4 patients and comminuted anterior wall in 4 patients. According to the fracture side; right-sided anterior wall was fractured in 7 patients and leftsided wall in 4 patients and bilateral wall fractures detected in 5 patients. Associated supra orbital rim fracture was detected in 10 patients but none had orbital roof fractures.

Associated facial fractures included: Zygomaticomaxillary complex and arch fractures in 7 cases and naso-orbital ethmoid (NOE) type-I in one patient and nasal fracture in one patient.

Coronal approach was the standard surgical approach in 13 cases; but pre-existing wounds were accessed in 3 cases. Fixation with low profile 1.5 $\mathrm{mm}$ miniplate system were applied in all patients.

Post-operative follow-up period ranged from 6-12 months. Clinical data revealed that none of the patients complained from these miniplates concerning its palpability under the skin, sensitivity to temperature changes (hot and cold weather). Also, no plate exposure or extrusion recorded.

However, only two patients had wound infections that resolved by intense antibiotic therapy. 
Patients complained only from minor symptoms such as post-operative pain, supraorbital paresthesia and facial edema (resolved within 7 to 10 days).

Post-operative CT imaging showed good fracture healing, good alignment of the anterior wall and no plate failure (fracture). Patients were satisfied with restoration of the forehead contour and excellent aesthetic results.

\section{Cases presentations:}

Case No. 2: (Fig.1):

A 22 years old male patient admitted to trauma unit after he sustained motor car accident. He presented with forehead depression and periorbital swelling, (Fig. 1A). CT imaging showed severely displaced right anterior wall and supraorbital rim fractures without injury of the nasofrontal duct, intact posterior table and associated with right frontozygomatic suture fracture (Fig. 1B,C).

Under general anesthesia, the fracture was accessed through a coronal incision (Fig. 1D), then exploration of the sinus, fracture reduction and fixation with low profile miniplate was performed (Fig. 1E). Restoration of forehead contour was achieved (Fig. 1F). After 14 days, postoperative CT imaging showed good alignment of bone (Fig. $1 \mathrm{G}, \mathrm{H})$. No evidence of complications was found 12 months post-operatively.
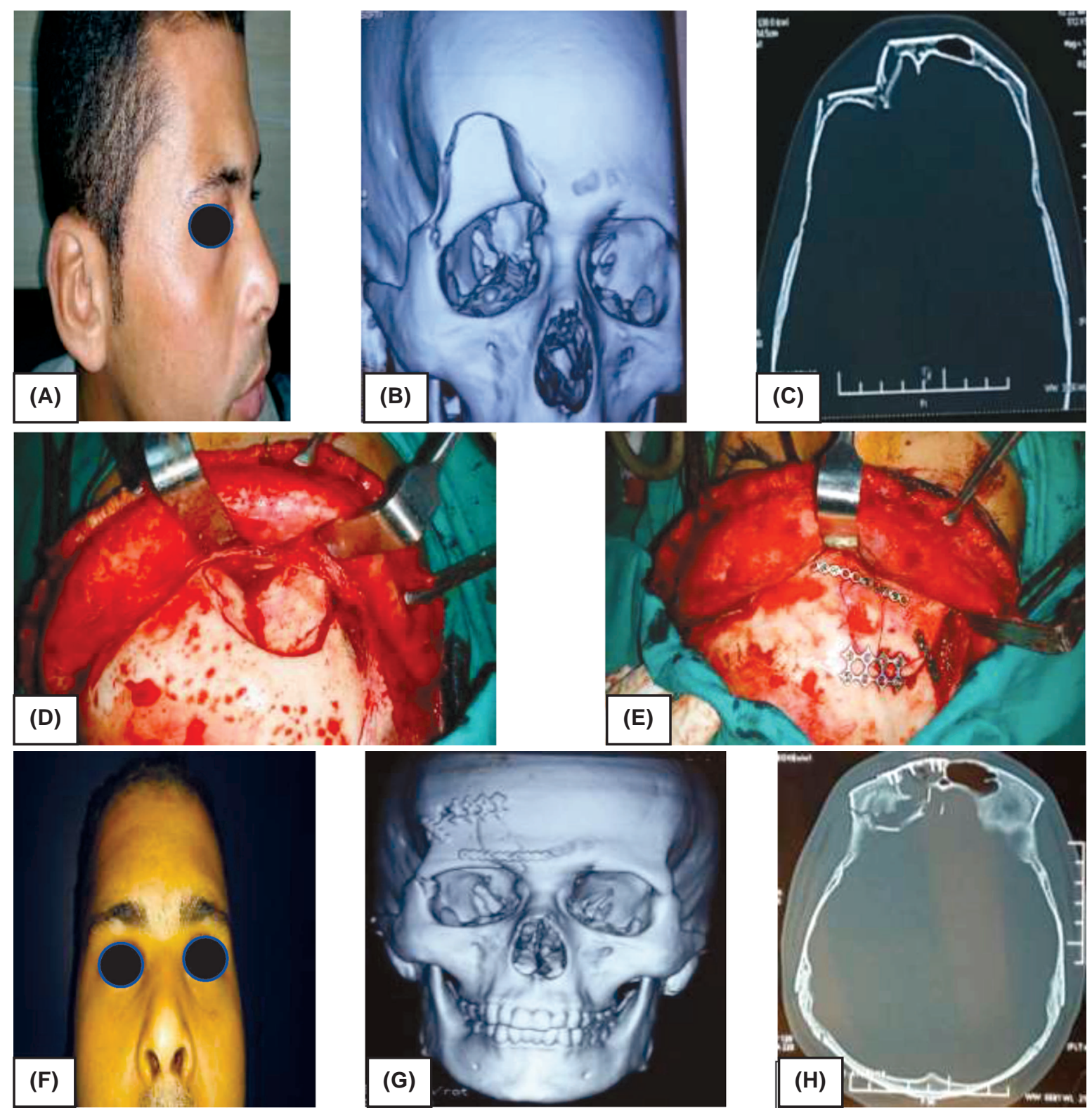

Fig. (1): Case No. 2: A 22 years old male patient with frontal sinus fracture due to motor car accidents: (A): Preoperative photo showed right sided forehead depression. (B): 3D CT showed severely displaced right frontal sinus, supraorbital rim fractures and right frontozygomatic fracture. (C): Axial CT scan showed severely displaced right anterior wall fracture. (D): Coronal approach showed displaced fracture segments. (E): Fixation of the fracture segments with low profile miniplates. (F): Postoperative photo after 14 days showed restoration of forehead contour. (G): 3D CT after 14 days showed good alignment of bone. $(\mathrm{H})$ : Axial CT scan after 14 days. 
Case No. 4: (Fig. 2):

A 29 years old male patient sustained an assault injury. He presented with lacerated forehead wound, palpable step off and periorbital ecchymosis. CT scan showed moderately displaced left anterior wall and supraorbital rim fractures without injury of the nasofrontal duct or the posterior table (Fig.
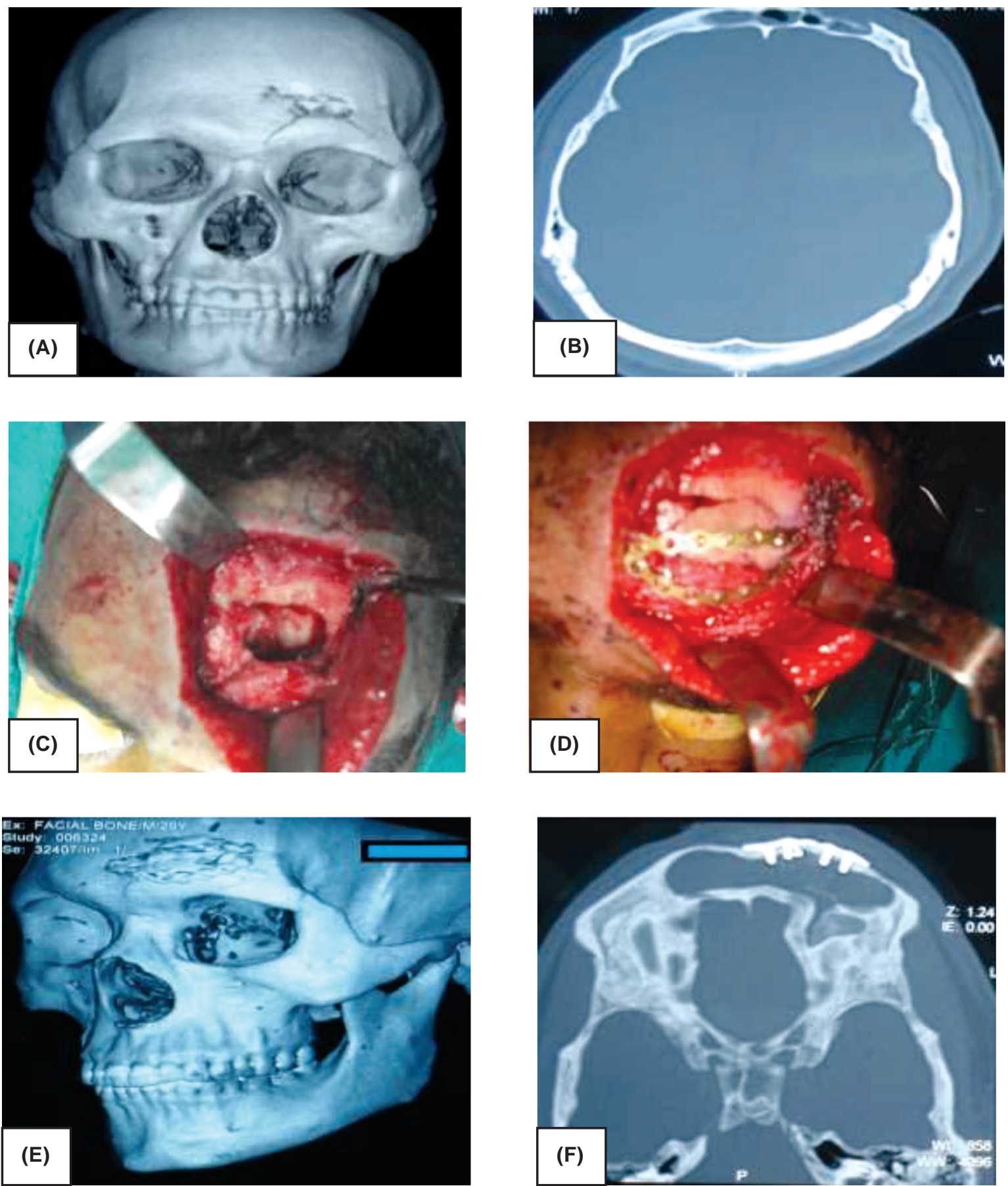

Fig. (2): Case No. 4: A 29 years old male patient with frontal sinus fracture due to assault. (A): 3D CT showed moderately displaced left anterior wall fracture. (B): Axial CT scan showed the fracture. (C): External wound approach showed the fracture. (D): Fixation of the fracture segments with low profile miniplates. (E): 3D CT scan after 10 days showed good alignment of bone. (F): Axial CT scan after 10 days. 
Case No. 6: (Fig. 3):

A 34 years old male patient sustained a motor car accident. He presented with lacerated forehead wound, palpable step off and periorbital ecchymosis. CT scan showed moderately displaced right anterior wall and supraorbital rim fractures without injury of the nasofrontal duct and the posterior
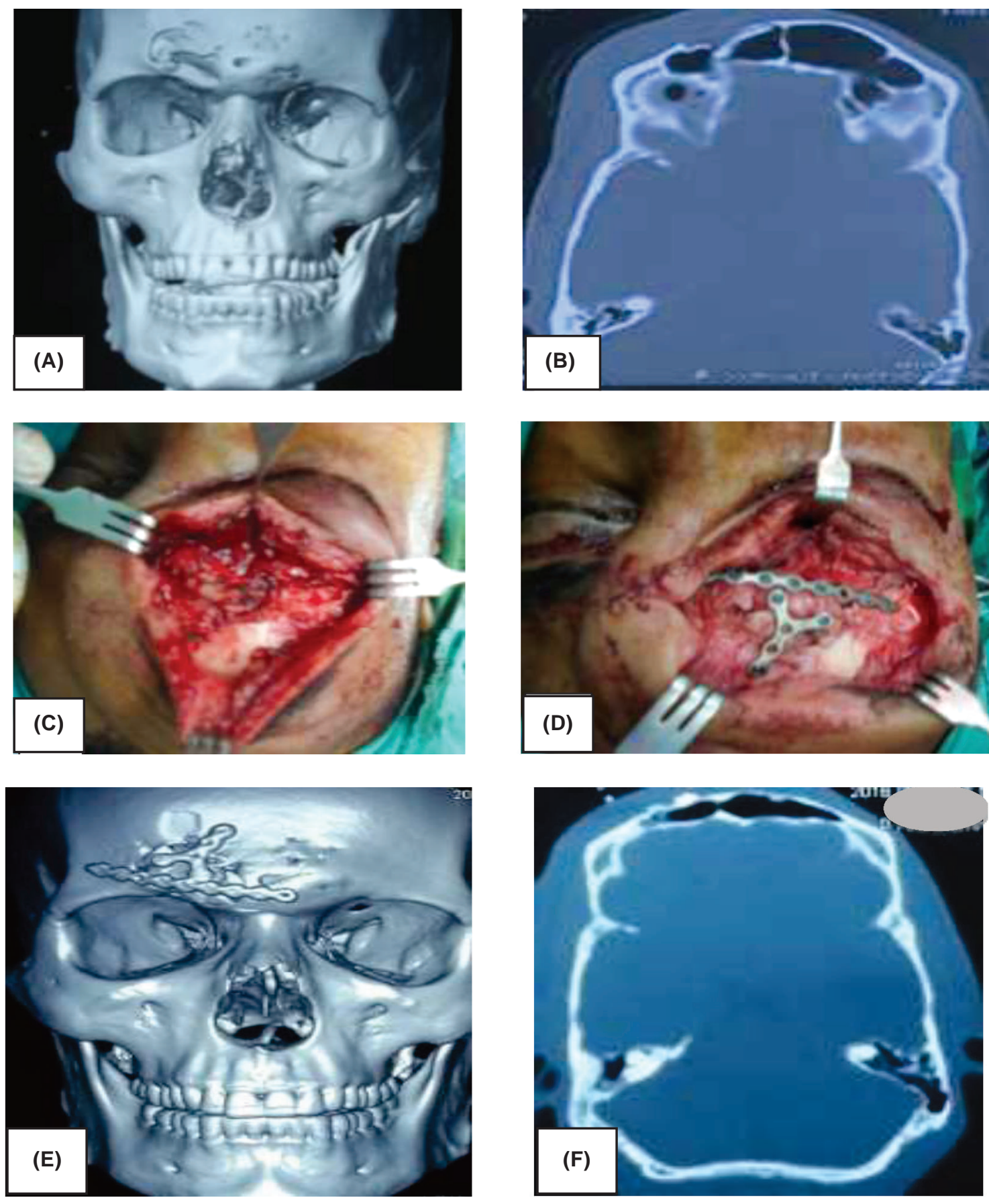

Fig. (3): Case No. 6: A 34 years old male patient with frontal sinus fracture due to motor car accidents: (A): 3D CT showed moderately displaced right anterior wall fracture. (B): Axial CT scan showed the fracture. (C): External wound approach showed the fracture. (D): Fixation of the fracture segments with low profile miniplates. (E): 3D CT scan after 14 days showed good alignment of bone. (F): Axial CT scan after 14 days. 
Case No. 10: (Fig. 4):

A 19 years old male patient sustained a motor car accident. He presented with forehead depression and periorbital swelling, (Fig. 4A). CT imaging showed comminuted bilateral anterior wall and supraorbital rim fractures without injury of the nasofrontal duct, the posterior table and associated with nasal fracture (Fig. 1B,C). Under general anesthesia, the fracture was accessed through a coronal incision (Fig. 1D), then exploration of the sinus, fracture reduction and fixation with low profile miniplate was performed (Fig. 1E). Restoration of forehead contour was achieved (Fig. 1F). Post-operative CT imaging showed good alignment of bone after 16 days (Fig. 1G,H). No evidence of complication was found 10 months post-operatively.
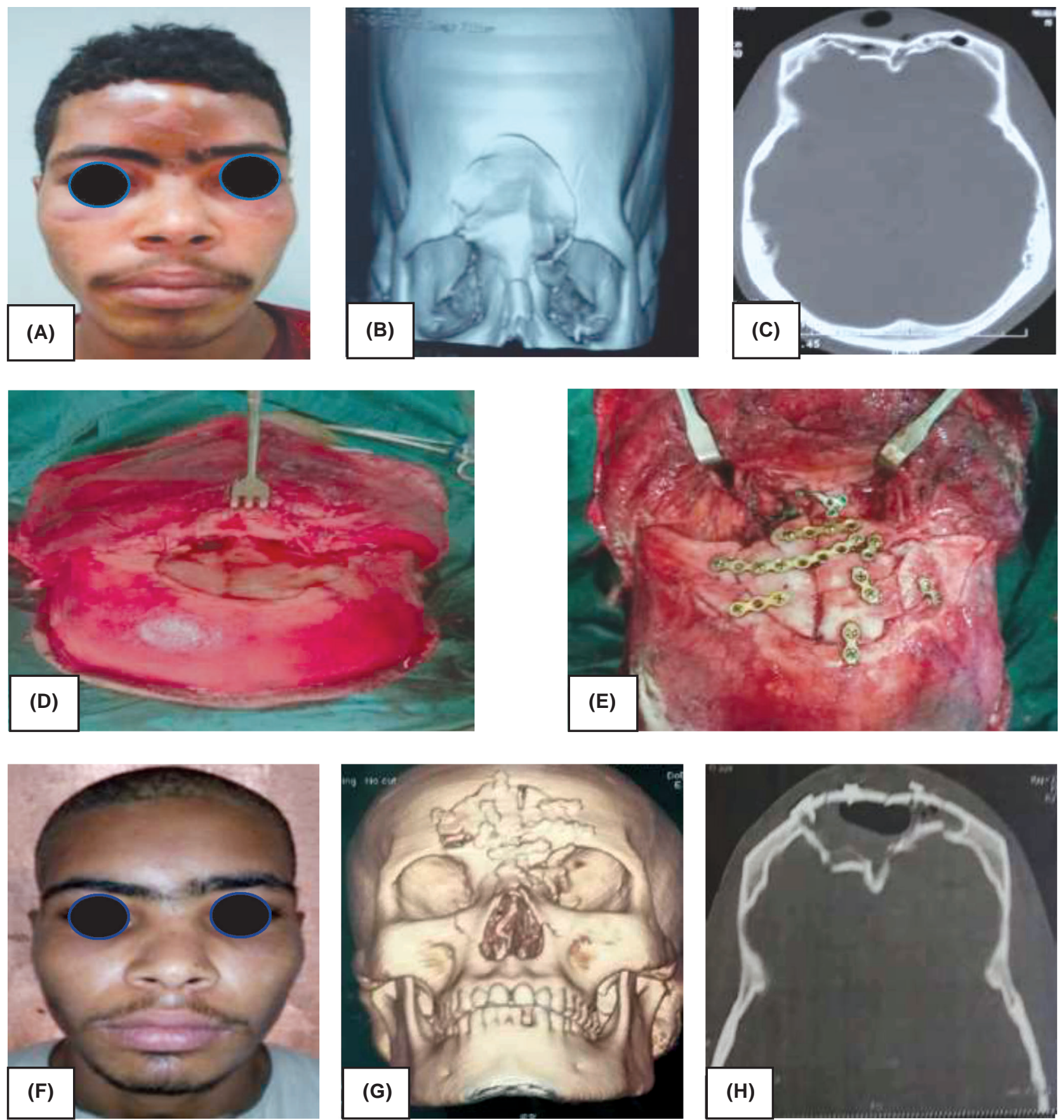

Fig. (4): Case no.10: A 19 years old male patient with frontal sinus fracture due to motor car accidents: (A): Preoperative photo showed central forehead depression. (B): 3D CT showed bilateral comminuted anterior wall with supraorbital bar and nasal fracture. (C): Axial CT scan showed bilateral comminuted anterior wall. (D): Coronal approach showed displaced fracture segments. (E): Fixation of the fracture segments with low profile miniplates. (F): Postoperative photo after 16 days showed restoration of forehead contour. $(\mathrm{G})$ : 3D CT after 16 days showed good alignment of bone. (H): Axial CT scan after 16 days. 


\section{DISCUSSION}

Frontal sinus and supraorbital rim fractures are associated with high-velocity injury craniomaxillofacial trauma. They usually occur in young adults between 20 and 40 years of age, encompassing the group of social workers in which cosmetic deformity can cause a significant disability for them [8,9]. Therefore, surgical reduction and fixation of the upper-third facial fractures is often indicated to reconstruct the aesthetic disfigurements arising from disrupted bone profile in these young patients [10].

These fractures range from linear in place or minimally/moderately displaced fractures to severely displaced and comminuted fractures. The fracture pattern depends on the nature and degree of trauma sustained, the size and degree of pneumatization of the sinus. Linear or minimally displaced fractures carry little or no risk of cosmetic deformity, CSF leak, functional deficit of frontal sinus or development of a mucocele and hence can be managed conservatively by periodic observation $[11,12]$.

If the degree of displacement; as visualized on axial or sagittal sections of CT scans; is $>4 \mathrm{~mm}$ (that is more than a table's width), it warrants an open reduction and fixation within 7-10 days, not only to correct the forehead contour irregularity, but also to release any mucosal entrapment at the edges of the fracture, which could otherwise lead to late mucocele formation or chronic frontal sinusitis [13]. More severe injuries resulting in severe displacement $(>6 \mathrm{~mm})$ or comminution of the outer table require meticulous repositioning, stabilization, and fixation of the fragments in order to prevent earlier neurological deficits and cosmetic contour deformity later on [14].

With the advent use of titanium plating system, open reduction and internal fixation of significant displacement of anterior table fracture become applicable. Frontal bone and sinus region had no force applied on it unlike the mandible; only movable bone in the facial skeleton; that had much force due to its muscular attachments. The size of plating system is chosen according to bone thickness, fracture pattern, type of bone or buttress affected [15].

In open reduction and internal fixation of anterior table of frontal sinus, titanium micro plating system $(1.1 / 1.3 \mathrm{~mm})$ is usually applied to counteract the physiological loads that are transmitted to the frontal bar. This micro system carries the following advantages: non-palpable under the skin, less in- fection, less temperature sensitivity and no artifact on computed tomographic imaging.

Undoubtedly, thicker miniplates are more likely to be palpable under the forehead skin and are worthless from a biomechanical point of view [16].

However, some studies reported that a low profile miniplate system $(1.5 \mathrm{~mm})$ can be applied in anterior table fractures with satisfactory results even in severe and comminuted fracture types and in reconstruction of anterior wall frontal sinus by bone graft. Satyanarayana et al., reported a review on fixation of frontal sinus fractures with low profile miniplating system [17]. Nguyen et al., fixed anterior wall fracture by low profile $1.5 \mathrm{~mm}$ plating system through upper eyelid approach with excellent aesthetic outcomes [18].

Silva et al., treated frontal bone fracture sequel through inversion of bone fragment and fixed it by low profile $1.5 \mathrm{~mm}$ miniplates [19]. Zavattero et al., used 1.5 titanium mesh fixed with $1.5 \mathrm{~mm}$ screws for reconstruction of comminuted anterior wall frontal sinus fracture [20]. Faverani et al., reported a case with severely displaced anterior wall that fixed with low profile $1.5 \mathrm{~mm}$ plates and screws with good results [21].

In this study, sixteen young male adults (social workers) with isolated anterior wall fracture were treated with low profile miniplate system $(1.5 \mathrm{~mm})$. Majority of their fractures were due to motor car accidents as the most common cause in our country. In postoperative clinical follow-up, none of them reported complaints from these plates concerning its palpability under the skin, sensitivity to temperature changes, or plate extrusion. Only two patients had wound infections. On CT imaging analysis, good fracture healing and good alignment of the anterior wall. All patients had satisfied with restoration of the forehead contour and excellent aesthetic results.

Our limitations in this study is the small number of patients that enrolled in the study, other limitation is lack of a mechanical test for evaluating these plates and its effects on osteointegration, liability to corrosion and fracture stability when applied to anterior table fracture.

\section{Conclusion:}

Isolated anterior wall frontal sinus fractures are common due to high incidence rate of motor car accidents in our country. Main lines of treatment aimed to restore a functional safe sinus, prevent contour deformity and obtain goo daesthetic results. These goals can be obtained by fracture 
fixation with this low profile miniplate system with resultant patient satisfaction.

Conflict of interest: Non declared.

Source of funding: None.

\section{REFERENCES}

1- Rodriguez E.D., Stanwix M.G., Nam A.J., et al.: Twentysix-year experience treating frontal sinus fractures: A novel algorithm based on anatomical fracture pattern and failure of conventional techniques. Plast. Reconstr. Surg., 122 (6): 1850-66, 2008.

2- Bell R.B., Dierks E.J., Brar P., Potter J.K. and Potter B.E.: A protocol for the management of frontal sinus fractures emphasizing sinus preservation. J. Oral Maxillofac. Surg., 65 (5): 825-39, 2007.

3- Chegini S., Gallighan N., Mcleod N., et al.: Outcomes of treatment of fractures of the frontal sinus: Review from a tertiary multispecialty craniofacial trauma service. $\mathrm{Br}$. J. Oral Maxillofac. Surg.; 54 (7): 801-5, 2016.

4- Fox P.M., Garza R., Dusch M., Hwang P.H. and Girod S.: Management of frontal sinus fractures: Treatment modality changes at a level I trauma center. J. Craniofac. Surg., 25 (6): 2038-42, 2014.

5- Choi M., Li Y., Shapiro S.A., Havlik R.J. and Flores R.L.: A 10-year review of frontal sinus fractures: Clinical outcomes of conservative management of posterior table fractures. Plast. Reconstr. Surg., 130 (2): 399-406, 2012.

6- Chen K.T., Chen C.T., Mardini S., Tsay P.K. and Chen Y.R.: Frontal sinus fractures: A treatment algorithm and assessment of outcomes based on 78 clinical cases. Plast. Reconstr. Surg., 118 (2): 457-68, 2006.

7- Tedaldi M., Ramieri V., Foresta E., Cascone P. and Iannetti G.: Experience in the management of frontal sinus fractures. J. Craniofac. Surg., 21 (1): 208-10, 2010.

8- El Khatib K., Danino A. and Malka G.: The frontal sinus: a culprit or a victim? A review of 40 cases. J. Craniomaxillofac. Surg., 32 (5): 314-17, 2004.

9- Piccolino P., Vetrano S., Mundula P., Di Lella G., Tedaldi M. and Poladas G.: Frontal bone fractures: New technique of closed reduction. J. Craniofac. Surg., 18 (3): 695-8, 2007.

10- Strong E.B.: Frontal sinus fractures: Current concepts. Craniomaxillofac Trauma Reconstr., 2 (3): 161-75, 2009.

11- Manolidis S. and Hollier L.H. Jr.: Management of frontal sinus fractures. Plast. Reconstr. Surg., 120 (7 Suppl 2): 32S-48S, 2007.

12- Noury M., Dunn R.M., Lalikos J.F., Fudem G.M. and Rothkopf D.M.: Frontal sinus repair through a frontalis rhytid approach. Ann. Plast. Surg., 66 (5): 457-9, 2011.

13- Hwang K. and Song Y.B.: Closed reduction of fractured anterior wall of the frontal bone. J. Craniofac. Surg., 16 (1): 120-2, 2005.

14- Koudstaal M.J., van der Wal K.G., Bijvoet H.W., Vincent A.J. and Poublon R.M.: Post-trauma mucocele formation in the frontal sinus; a rationale of follow-up. Int. J. Oral Maxillofac. Surg., 33 (8): 751-4, 2004.

15- Guy W.M. and Brissett A.E.: Contemporary management of traumatic fractures of the frontal sinus. Otolaryngol. Clin. North Am., 46 (5): 733-48, 2013.

16- Doonquah L., Brown P. and Mullings W.: Management of frontal sinus fractures. Oral Maxillofac. Surg. Clin. North Am., 24 (2): 265-72, 2012.

17- Sathyanarayanan R., Raghu K., Deepika S. and Sarath K.: Management of Frontal Sinus Injuries. Ann. Maxillofac. Surg., 8 (2): 276-80, 2018.

18- Nguyen D., Hakimi M., Sinha S.R. and Martin M.: Upper Eyelid Approach for the Reconstruction of Isolated Fractures of the Anterior Wall of the Frontal Sinus. J. Craniofac. Surg., 29 (7): 1903-5, 2018.

19- Silva J.R., Mourão C.F., Rocha Júnior H.V., Magacho L.F., Moraes G.F. and Homsi N.: Treatment of frontal bone fracture sequelae through inversion of the bone fragment. Rev. Col. Bras Cir., 43 (6): 472-5, 2016.

20- Zavattero E., Boffano P., Bianchi F.A., Bosco G.F. and Berrone S.: The use of titanium mesh for the reconstruction of defects of the anterior wall of the frontal sinus. J. Craniofac. Surg., 24 (2): 690-1,2013.

21- Faverani L.P., Ferreira S., Momesso G.A., et al.: Surgical treatment of severe frontal bone fracture. J. Craniofac. Surg., 26 (3): 229-1, 2015. 